\title{
The New Drug Research Strategy in Rheumatoid Arthritis
}

\author{
Evija Stumbra* \\ MD Rheumatologist, Internal Medicine Specialist, Riga 1 St Hspital, Latvia, Europe \\ *Corresponding author: Evija Stumbra, MD Rheumatologist, Internal Medicine Specialist, Riga 1 St Hspital, Latvia, Europe
}

\begin{tabular}{lll}
\hline ARTICLE INFO & & ABSTRACT \\
\cline { 1 - 1 } $\begin{array}{l}\text { Received: 㹃February 05, } 2019 \\
\text { Published: }\end{array}$ & & $\begin{array}{l}\text { Citation: Evija Stumbra. The New Drug Research Strategy in Rheumatoid Arthritis. Bi- } \\
\text { omed J Sci \& Tech Res 14(2)-2019. BJSTR. MS.ID.002532. }\end{array}$ \\
\hline
\end{tabular}

\section{Editorial}

Globally, new treatment strategies have evolved basing on many clinical trials and new drug research results. According to the data of U.S. National Library of Medicine (ClinicalTrials.gov), only 2439 studies have been conducted on rheumatoid arthritis (RA). Traditional synthetic DMARDs have been available in treating RA patients for a long time, not giving necessary treatment results to severe arthritis patients, who are in great need for arrival of new biological drugs.

In developing countries biological drug treatment can be achieved in several ways - receiving them from the government, however, a reduced amount of patients can receive it less than it is necessary or another option - a drug research study. The last of course is challenging both for physician and patient. We all have to take into account both very good and bad results, including deaths. So, the trust of the patient to his doctor and doctor's team is remarkable.

The doctor himself must have strong confidence that the Sponsor and his Team will give support and necessary information about to new drug safety and tolerance. In real life, there are several steps that minimize this confidence to CRO clinical research organizations) and their team, which includes not only medical professionals, but also lawyers, economists and financiers, who's most important interests are bound to money and profit making. We must realize that the pharmaceutical industry is one of the leading and most profitable in the world nowadays.

The first part is the contracts, where we can see a lot of amendments, sections that are written for the benefit of companies that have recruited millions. For example, the Principal Investigator (PI) has to provide the whole team and patients with insurance

policies. Unfortunately, there are not many insurance companies that would accept that kind of deal and what is more it would cost a lot of money. Therefore, the contract negotiation period is quite long because the lawyers must keep their company's money safe. The other possibility is to make a deal with another medical professional who has not read the whole contract or does not raise objections to it. Another section states that all documentation must be handed over to Sponsor or his representatives immediately, after request.

The PI has to continue the study even when the reimbursement from CRO has not arrived, it involves also patient travel expenses, that have to be paid to patients otherwise the patient might complain to the Ethics Committee for not receiving what he has the rights to receive. After study visits the payments arrive in a period of 3-6 months after data verification. What can be done during this period if the study protocol requires frequent visits? It is always the PI's responsibility and problem.

The PI can inform the representatives of CRO and sometimes be lucky to inform the medical team of the Sponsor, but typically, they are not very worried about the situation or deliver your letter to another department which could be more appropriate to your problem. Sometimes, the problem is not about scheduled visits, but about the unscheduled ones, which also have to be provided in case of blood clotting tests, bad ECG reports, need to repeat ECG or other tests, which are not mentioned in the contract or budget and then it is the PI, who has to pay for further research and diagnosis of the patient.

Therefore, the PI has to be inventive and, in such moments, deal with several problems at once - treating the patient from disease 
and side effects of drugs and finding funding to pay for extra examinations. Finally, the Medical monitors from Sponsor's side may ask from you detailed information about troponin or other tests performed that are not even mentioned in the protocol, but anyway have to be done for the sake of the patient. The question is are we all really so altruistic, do all the above-mentioned people from big pharmaceutical companies also work relying on charity,

ISSN: 2574-1241

DOI: 10.26717.BJSTR.2019.14.002532

Evija Stumbra. Biomed J Sci \& Tech Res

(c) (i) This work is licensed under Creative

Submission Link: https://biomedres.us/submit-manuscript.php believing that one day their efforts will pay off. Or do they still receive a monthly salary for doing their job? Or perhaps there is only one naive side here who believes that one day there will be appropriate medicine and pharmaceutical companies that will pay for the work performed, rather than looking for a way to withdraw from the contract.

$\begin{array}{ll}\text { BIOMEDICAL } & \text { Assets of Publishing with us } \\ \text { RESEARCHES } & \text { - Global archiving of articles } \\ & \text { - Immediate, unrestricted online access } \\ & \text { - Rigorous Peer Review Process } \\ & \text { - Authors Retain Copyrights }\end{array}$

